\title{
Multidecadal changes in the relationship between extreme temperature events in Uruguay and the general atmospheric circulation
}

\author{
Madeleine Renom • Matilde Rusticucci • \\ Marcelo Barreiro
}

Received: 7 June 2010/ Accepted: 22 December 2010/Published online: 8 January 2011

(C) Springer-Verlag 2011

\begin{abstract}
We analyze changes in the relationship between extreme temperature events and the large scale atmospheric circulation before and after the 1976 climate shift. To do so we first constructed a set of two temperature indices that describe the occurrence of warm nights (TN90) and cold nights (TN10) based on a long daily observed minimum temperature database that spans the period 1946-2005, and then divided the period into two subperiods of 30 years each (1946-1975 and 1976-2005). We focus on summer (TN10) and winter (TN90) seasons. During austral summer before 1976 the interannual variability of cold nights was characterized by a negative phase of the Southern Annular Mode (SAM) with a cyclonic anomaly centered off Uruguay that favoured the entrance of cold air from the south. After 1976 cold nights are associated not with the SAM, but with an isolated vortex at upper levels over South Eastern South America. During austral winter before 1976, the El Niño phenomenon dominated the interannual variability of warm nights through an increase in the northerly warm flow into Uruguay. However, after 1976 the El Niño connection weakened and the variability of warm nights is dominated by a barotropic anticyclonic anomaly located in the South Atlantic and a low pressure center over South America.
\end{abstract}

\footnotetext{
M. Renom $(\square) \cdot$ M. Barreiro

Unidad de Ciencias de la Atmósfera, Instituto de Física, Facultad de Ciencias, Universidad de la República, Iguá 4225, 11400 Montevideo, Uruguay

e-mail: renom@fisica.edu.uy

M. Rusticucci

Departamento de Ciencias de la Atmósfera y los Océanos, Facultad de Ciencias Exactas y Naturales, Universidad de Buenos Aires, Int. Güiraldes 2160, Ciudad Universitaria Pab II, 1428 Buenos Aires, Argentina
}

This configuration also strengthens the northward flow of warm air into Uruguay. Our results suggest that changes in El Niño evolution after 1976 may have played a role in altering the relationship between temperature extreme events in Uruguay and the atmospheric circulation.

Keywords Extreme temperature events · Multidecadal variability 1976 climate shift $\cdot$ Uruguay-Southeastern South America $\cdot$ ENSO $\cdot$ SAM

\section{Introduction}

In the last years there has been increased interest in understanding climate extreme events due to their social and environmental impacts. To do so it is necessary to study the principal modes of climate variability in which the extreme events are embedded, which is not only crucial for future projections under an anthropogenic climate change or for multidecadal variability, but also for climate models to better represent them. A major obstacle for achieving this is the requirement of high quality and high frequency datasets that are usually not available. Moreover, even though several papers have documented observed changes in extreme temperature events in, for example, South America the different methodologies employed to define extreme events make the comparison a difficult task.

Based on the work of Frich et al. (2002) a first set of socalled climate extreme events was developed by the Expert Team on Climate Change Detection, Monitoring and Indices (ETCCDMI). They defined a set of 27 climate indices, which describe different extreme events (see Vincent et al. 2005; Alexander et al. 2006; Haylock et al. 2006 for more detail). A sub-set of the aforementioned set is that of threshold indices based on the exceedance of a 
determined percentile of the climatological distribution. The strength of this type of indices relies in that by removing the local climatology they allow regional and global intercomparison of the extreme event considered. Using the definition of extremes suggested by the ETCCDMI group several studies detected a warming across South Eastern South America (SESA) during austral summer and winter. This warming has been detected in the mean and in the extremes, and is more robust for winter than for summer: Vincent et al. (2005) for South America, Rusticucci and Barrucand (2004) for Argentina, Marengo and Camargo (2008) for southern Brazil and Rusticucci and Renom (2008) for Uruguay.

In order to determine how the global climate models represent extreme climate events, Rusticucci et al. (2010) and Marengo et al. (2010) made an intercomparison between the observed and the simulated extreme events over South America for the period 1961-2000. They analyzed the performance of eight global coupled climate models from the Fourth Assessment Report of the Intergovernmental Panel of Climate Change (IPCC-AR4) in reproducing historical trends, mean values and the variability of two indices based on extreme temperature (frost days and warm nights), and three indices based on rainfall. For the region of La Plata basin (within SESA), they found that indices based on thresholds were those which were best represented by the General Circulation Models (GCMs).

With regard to long-term changes in extreme events, there is still an open question whether they are related to large scale circulation patterns and whether or not that relationship can change over time. To address these questions Kenyon and Hegerl (2008) analyze the influence of the principal modes of climate variability on global extreme temperature by selecting three indices that characterize three of the major large-scale circulation patterns: the Cold Tongue Index (CTI), which represents the El Niño-Southern Oscillation (ENSO), the North Pacific Index (NPI), which represents the Pacific multidecadal variability, and the North Atlantic Oscillation (NAO). Overall, they found that changes in the aforementioned modes affect the global extreme temperature events. Moreover, they suggest that for South America-for which they have very little information-El Niño phenomenon, has significant influence in the occurrence of warm nights, primarily during the austral summer. In addition, they also concluded that the NPI has a stronger influence than ENSO in the minimum temperature cold extremes in the Southern Hemisphere.

Another dominant mode of variability that needs to be taken into account in the Southern Hemisphere is the Southern Annular Mode (SAM) (Kidson 1999; Mo 2000, etc.) which is characterized by a symmetric or zonal annular structure between polar regions and mid-latitudes. A positive (negative) phase of SAM is characterized by a negative (positive) anomaly in Sea Level Pressure (SLP) in the Antarctic region (south of $60^{\circ} \mathrm{S}$ ) and positive (negative) anomaly in middle latitudes, which strengthens (weakens) the surface westerlies. Previous studies documented a significant positive trend in SAM since the mid-1960s (Thompson and Wallace 2000; Marshall 2003) that is most significant during summer (Thompson and Solomon 2002; Marshall 2003; Arblaster and Meehl 2006). However, to date it is not clear whether this trend is related to the changes in stratospheric ozone during austral summer and fall (Thompson and Solomon 2002; Gillett and Thompson 2003) or due to natural forcing or variability (Marshall et al. 2004; Arblaster and Meehl 2006). Most of the studies that associate the SAM and climate variability in South America have so far focused in the spring season (Barrucand et al. 2008 for extreme temperature, Silvestri and Vera 2009 for rainfall, etc.).

It is well documented that around 1976/1977 the sea surface temperature pattern of the Pacific Ocean changed abruptly, with the tropical Pacific becoming warmer than in previous decades. This so-called climate shift of 1976/1977 is also evidenced by a qualitative change in large scale atmospheric circulation (Trenberth 1990; Zhang et al. 1997; Overland et al. 1999; Mantua and Hare 2002 e.g.). Accompanying this shift there are changes in rainfall patterns and in the relationship with the large scale circulation in South America (Boulanger et al. 2005; Kayano and Andreoli 2007; Antico 2008; Agosta and Compagnucci 2008; etc.). Analysing single station data, Rusticucci and Renom (2008) detected that changes in the Pacific Ocean affected particularly the minimum temperatures in Uruguay. Using a modelling approach, Barreiro (2009) studied the role of ENSO and the South Atlantic Ocean on the predictability of surface air temperature and rainfall over SESA focusing on inter-decadal time scales. His results show that the tropical Pacific is the main source of predictability for mean temperature mainly in late fall and winter (in agreement with previous observational studies like that of Barros et al. 2002) and, that the predictability changed significantly in the mid-1970s.

The objective of this study is to analyze changes in the relationship between the occurrence of extreme temperature events in Uruguay and the large scale circulation before and after the climate shift of 1976/1977. We hope to gain insight of the multidecadal variability of these events in order to later use the results for regional applications. Also having in mind future climate projections, we use threshold indices, which as pointed out above are better represented by models.

The paper is organized as follows: Sect. 2 includes a detailed description of the observed data used, the 
constructions of the extreme indices and the methods of analysis. The relationship between global SST and the atmospheric circulation anomalies associated with the extreme events in summer and winter is described in Sect. 3. The last section includes a summary and a discussion.

\section{Data and methodology}

The extreme indices considered in this study were obtained from a high-quality daily database of minimum temperature from 11 meteorological stations in Uruguay for the period 1946-2005. The quality control as well as the homogeneity assessment of the database are described in Rusticucci and Renom (2008) and were extended for all the stations considered here. Daily data was obtained from the Uruguayan National Meteorological Service (DNM, Dirección Nacional de Meteorología), and from the National Agricultural Research Institute (INIA, Instituto Nacional de Investigaciones Agropecuarias). The geographical distribution of the stations is shown in Fig. 1.

A set of two temperature indices representing the frequency of warm nights (TN90) and cold nights (TN10) was constructed using the RClimDex 1.0 software (freely available at http://www.cccma.seos.uvic.ca/ETCCDMI) for each station and calculated on a monthly basis. These warm and cold minimum temperature indices based on percentiles were calculated as the percentage of days in a month above (below) the 90th (10th) percentile (Vincent et al. 2005; Alexander et al. 2006). The percentiles were calculated from a 5-day window centered on each calendar day from the reference period 1976-2000. The selection of this reference period was motivated by the amount of data availability. It is important to mention that the version of

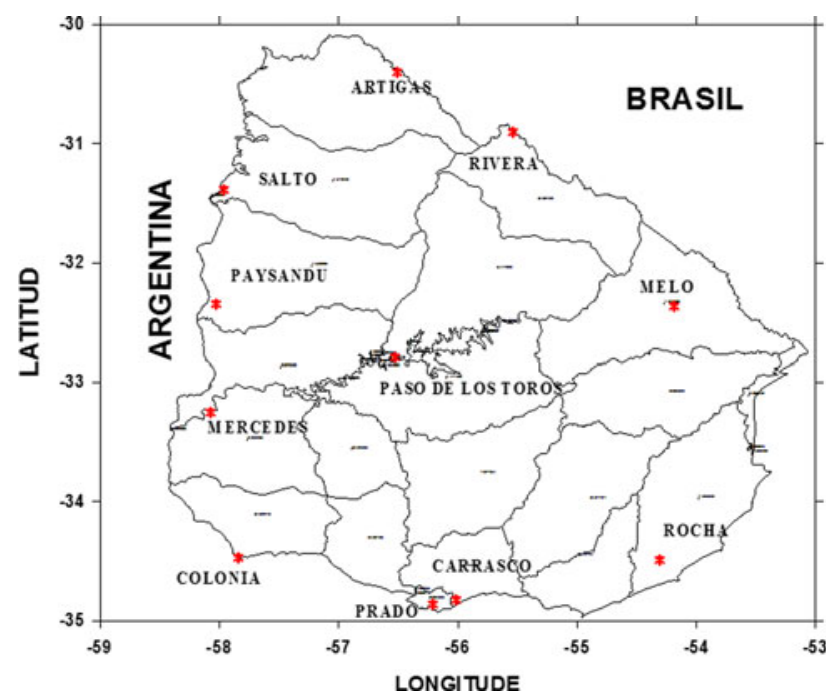

Fig. 1 Location of the eleven temperature stations analyzed the RClimDex used here takes into account the inhomogeneities and makes a correction at the boundaries of the reference period, as documented in Zhang et al. (2004). Since the software generates just monthly or annual indices the seasonal indices were constructed as the average of the monthly output for each period: 1946-1975 and 1976-2005 (hereafter called Period I and Period II, respectively). The analysis is performed for summer (December-JanuaryFebruary, DJF) and winter (June-July-August, JJA) seasons. The indices show significant linear trends (Rusticucci and Renom 2008) and were removed in each period in order to better isolate the inter-decadal variability. Once we have the index time series for each station in each season, we calculated Empirical Orthogonal Functions (EOFs) in order to obtain homogeneous regions of co-variability. This methodology was applied to Periods I and II. During both seasons of Period I most of the stations show similar behavior, except for the northeastern part of the country (Rivera and Melo stations). Thus, the index was constructed taking the average over nine stations. During Period II all the stations present an homogeneous behavior, and the index was constructed using all the available stations.

The monthly global-gridded Sea Surface Temperature (SST) used in this study is the Extended Reconstructed Sea Surface Temperature (ERSST v 3.0) at $2^{\circ} \times 2^{\circ}$ latitude longitude resolution (Smith et al. 2008). We consider the period 1946-2005, and divide it into the same subperiods as for the extreme indices. The SST anomalies (SSTa) were calculated removing the climatology of each corresponding period and, as for the extreme indices, the SSTa were detrended in each period separately.

To describe the atmospheric anomalies associated with the extreme indices we considered the Sea Level Pressure (SLP) and wind at $200 \mathrm{hPa}$ from the NCAR/NCEP Reanalysis data set (Kalnay et al. 1996). Since the Reanalysis starts in 1948 the maps for Period I consider only the time span 1949-1975 for summer and 1948-1975 for winter. The construction of the anomalies of the atmospheric variables was performed in the same way as described for the SSTa. The atmospheric variables were also detrended in the same way as the other time series analyzed.

In order to identify the regions of the global oceans that are related with the occurrence of temperature extreme events, as well as to determine if changes between different periods can be detected, a linear correlation analysis was performed for the two subperiods. The atmospheric anomalies related with the extreme indices are calculated by linearly regressing each field onto the extreme indices in Period I and Period II. The statistical significance of the correlations and regressions was assessed using a twotailed Student t-test, considering a significant level of 95\%. 
Rusticucci and Renom (2008) studied the spectrum of the temporal series of temperature indices in Uruguay using a multi tapper method. They found a peak between 3 and 6 years, particularly significant during winter in the TN90 index. On the other hand, they detected significant biennal variability particularly for the TN10 index during summer. Thus, to further understand the variability of extreme events in Uruguay we decided to analyze the TN10 index during summer and the TN90 index for winter.

\section{Results}

\subsection{Summer season (DJF)}

For summer season we analyzed the cold nights (TN10) index. Figure 2 shows the correlations and regresions between the index and SSTa, SLPa and $200 \mathrm{hPa}$ wind anomalies for Period I (1949-1975).

Overall, the cold nights index shows weak correlation with SSTa, with exception of the negative values in the tropical Indian Ocean (Fig. 2a). The structure of SLPa shows an annular pattern between the Antarctic region and
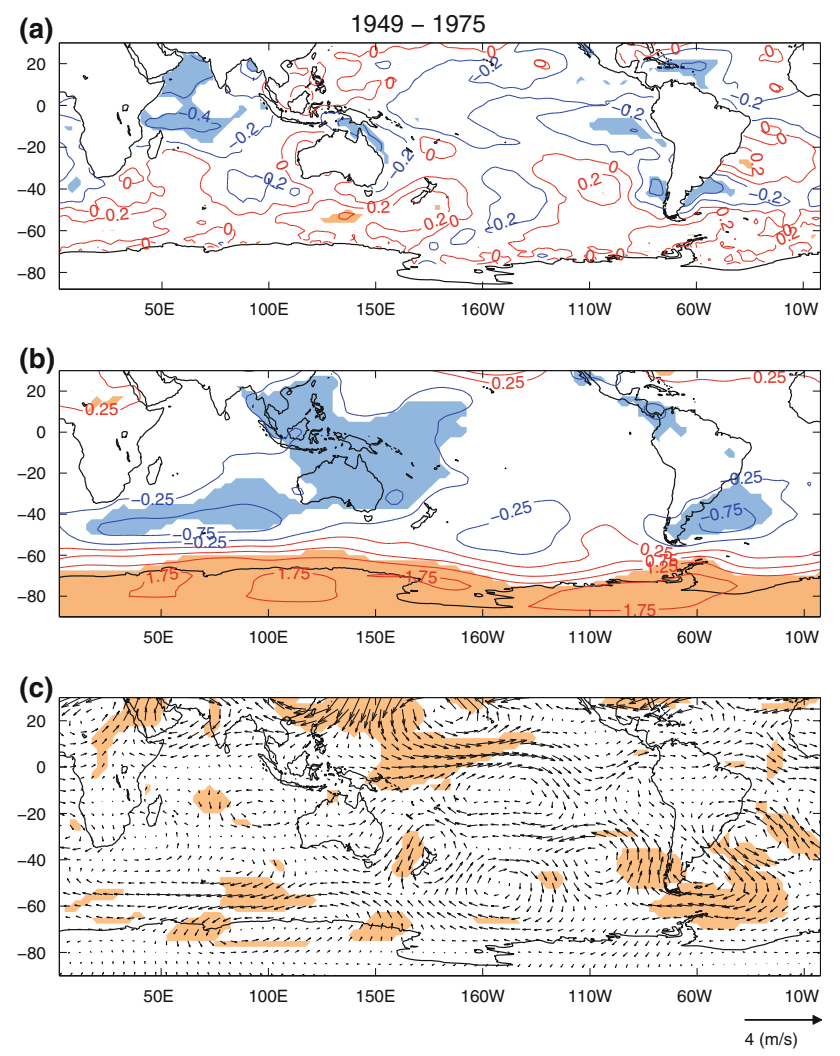

Fig. 2 Linear correlation between TN10 and SST anomalies (a), regressions maps of TN10 onto SLPa (b) and vector wind at $200 \mathrm{hPa}$ (c) for summer (DJF) during 1949-1975. Significant correlations at 95\% level are shaded the mid-latitudes of the Southern Hemisphere that is consistent with the anomaly observed in surface winds (not shown). This spatial structure resembles that of a negative phase of the Southern Annular Mode. To quantify the relationship suggested in the regression maps, we calculated the linear correlation between the TN10 and the detrended SAM indices (Marshall 2003, obtained from http://www.antarctica.ac.uk/met/gjma/sam.html) for the period 1958-1975 (the time period starts in 1958 because of the availability of the SAM index). As expected we found a negative correlation $(\mathrm{r}=-0.54)$ that is significant at the $95 \%$ level.

The regression maps also show a significant negative SLP anomaly in the southwestern Atlantic Ocean associated with an anomalous cyclonic circulation that extends from the surface to upper levels (Fig. 2b, c). This suggests a weakening of the South Atlantic anticyclone at the western limit that favours the entrance of cold air masses from the south to the region and leading to cold events.

During Period II (Fig. 3), one of the largest changes observed in the linear correlation between TN10 and SSTa is the loss of the significant negative correlation values in
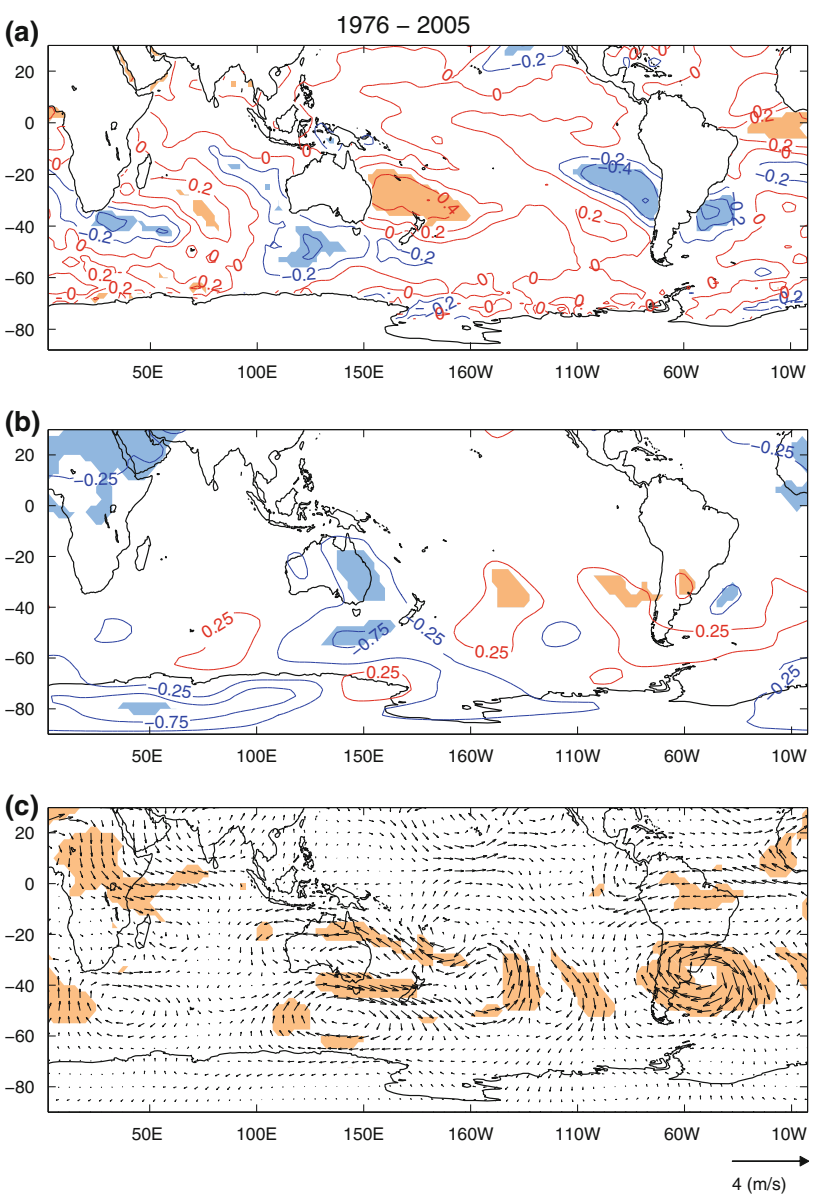

Fig. 3 Same as Fig. 2, but for the period 1976-2005 
the Indian Ocean (Fig. 3a). Some studies have shown the existence of a link between the Indian Ocean and frost events in South America that is accomplished through atmospheric teleconnections (Muller and Ambrizzi 2007). However, these are for the winter season and not for the summer. Our results suggest that further analysis is needed for a better understanding of the role that the Indian Ocean could play in climate variability over South America.

Concurrently, in this period there is an enhancement and northward displacement of the region with negative correlation off south Brazil and in the eastern coast of the South Pacific Ocean. Moreover, there are regions of positive correlation in the equatorial Atlantic and to the east of Australia, in the region of the South Pacific Convergence Zone (SPCZ). Interestingly, the annular pattern that dominated in Period I is absent. Instead, the variability of the TN10 is related to an isolated cyclonic circulation anomaly centered at $\left(35^{\circ} \mathrm{S}, 50^{\circ} \mathrm{W}\right)$ (Fig. $3 \mathrm{~b}$, c) just off Uruguay. This structure is also present in Period I, but is less well defined and located further southwest.

The SSTa correlation map suggests that the atmospheric anomalies are independent of ENSO. To understand the origin of the correlation between TN10 and SSTa off South America, we use a simplified atmospheric global circulation model (AGCM), SPEEDY (Molteni 2003); coupled to a slab ocean. In this setup, the SSTa are forced only by atmospheric heat fluxes and therefore there are no ENSO events. We run the model for 50 years and calculated the
Empirical Orthogonal Functions (EOFs) of the surface air temperature in a box defined by $\left[20-40^{\circ} \mathrm{S}\right.$ and $\left.65-45^{\circ} \mathrm{W}\right]$ inside SESA.

The 1st and 2nd EOFs explain 63 and $24 \%$ of the total variance, respectively.

Figure 4 shows the regression of SLPa and $200 \mathrm{hPa}$ wind anomalies onto the first two principal components as well as the correlations with SSTa. The circulation anomalies associated with the 2nd EOF show an annular pattern between the Antarctic region and the mid-latitudes of the Southern Hemisphere resembling the SAM, with largest weight in the southwestern South Atlantic where it forces significant SST anomalies. The circulation has a barotropic structure and in the upper levels an anticyclonic vortex located at the southernmost part of South America dominates. On the other hand, the 1st EOF consists of a barotropic vortex centered over the Patagonia at about $\left(60^{\circ} \mathrm{W}, 50^{\circ} \mathrm{S}\right)$. Negative SLPa coexist with negative SSTa in the Southeastern Pacific and in the region to the east of Australia, while there are positive SSTa around $30^{\circ} \mathrm{S}$ of both sides of the South American continent. Overall, we can observe that the regression patterns associated with the 2 nd EOF are very similar to the regression maps taking the TN10 as the independent index for Period I (see Fig. 2). On the other hand, the atmospheric anomalies associated with cold nights in summer during Period II seem to have characteristics of the first two EOFs.
Fig. 4 Regression of 1st EOF (left column) and 2nd EOF (right column) of surface air temperature obtained with SPEEDY, during DJF onto SLPa (contours) and significant correlations with SSTa (shaded) (upper panels) and regression onto $200 \mathrm{hPa}$ wind anomalies (lower panels)
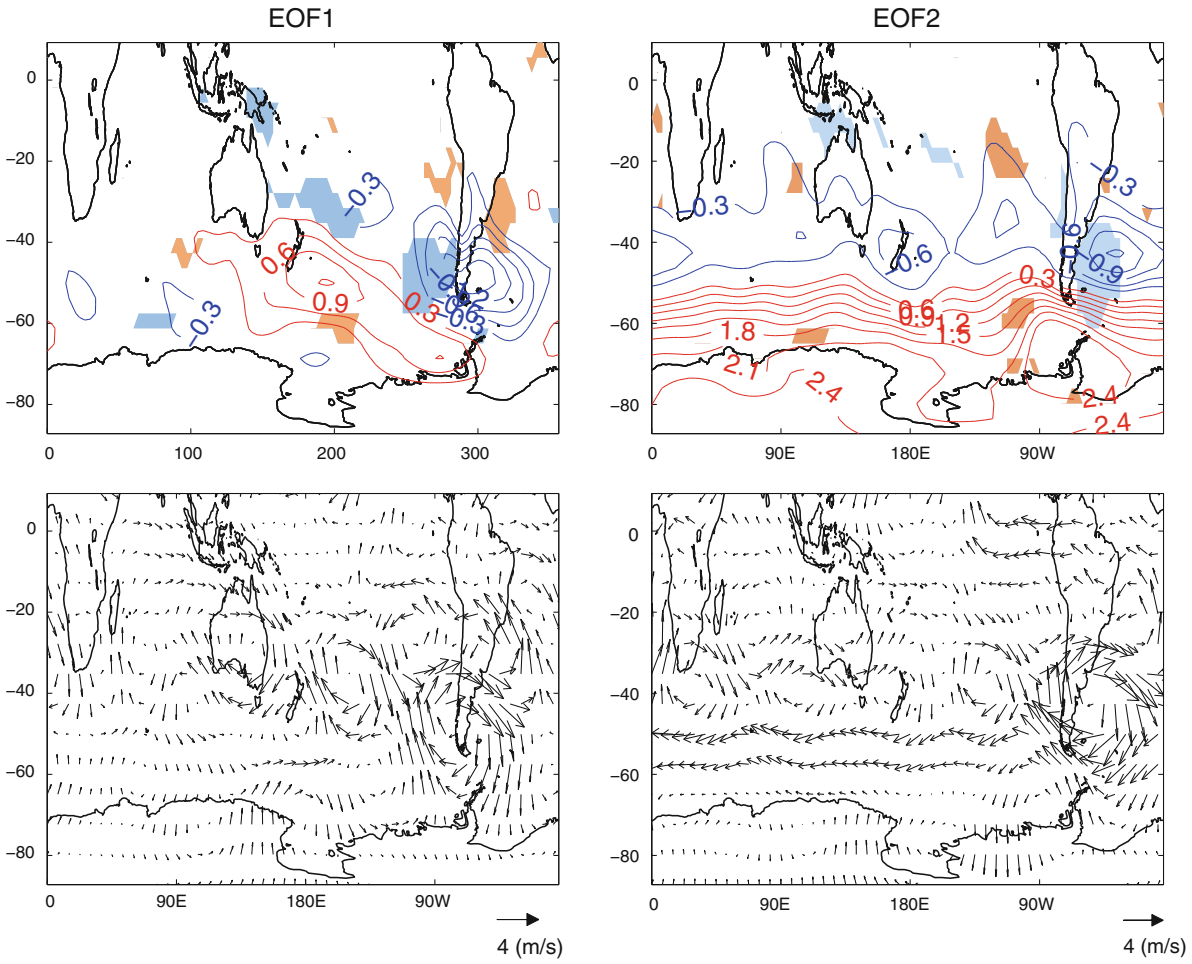
These results suggest that the SSTa related with the TN10 index are forced by the same atmospheric anomalies that influence the temperature over Uruguay, which in turn are due to the atmospheric internal variability.

\subsection{Winter season (JJA)}

For winter season we analyze the warm nights (TN90) index. Figure 5 shows the correlation and regression maps between the index and SSTa, SLPa and $200 \mathrm{hPa}$ wind anomalies during Period I (1948-1975). During this period there is a strong correlation with the equatorial Pacific Ocean. In agreement with the SSTa structure, the atmospheric anomalies associated with an increase in the occurrence of TN90 have an ENSO-like structure. For example, the SLPa resemble the negative phase of the Southern Oscillation and the $200 \mathrm{hPa}$ winds show a large anticyclonic circulation in the tropical Pacific to the south of the equator. The negative SLPa extend over South America increasing the northerly warm flow toward SESA. This suggests that for Period I ENSO events are highly correlated with the occurrence of warm nights during winter season. This is in agreement with Barros et al. (2002) who found a positive relationship with mean temperature anomalies in SESA and the occurrence of ENSO mainly during winter.
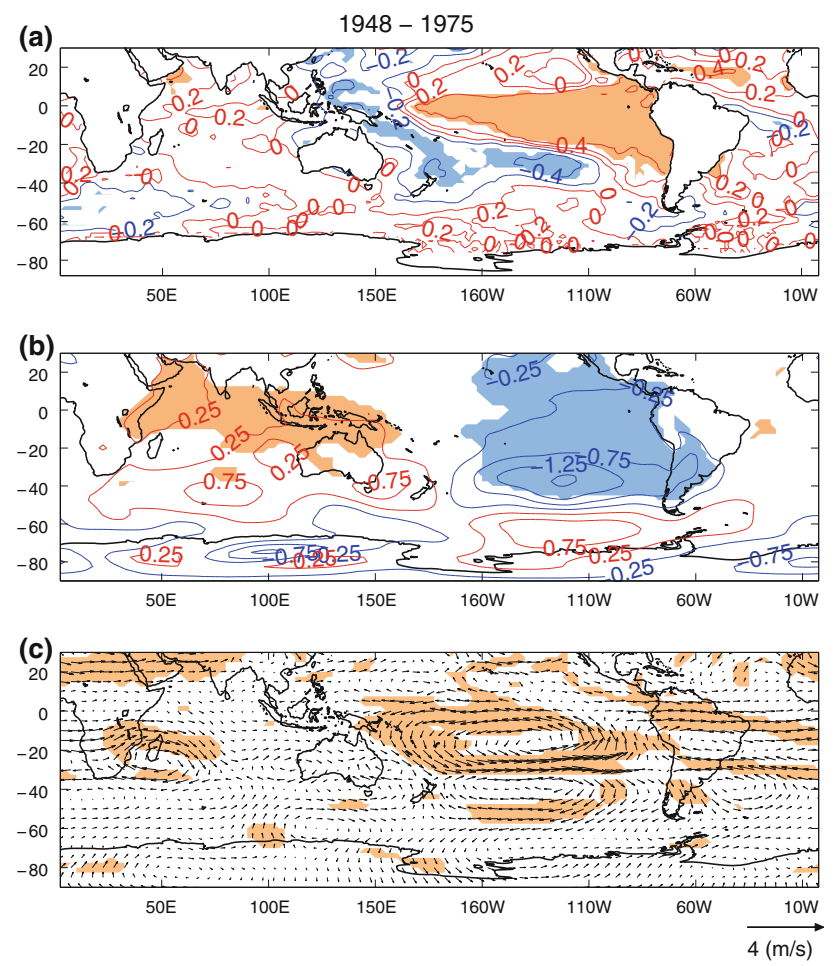

Fig. 5 Linear correlation between TN90 and SST anomalies (a), regressions maps of TN90 onto SLPa (b) and vector wind at $200 \mathrm{hPa}$ (c) for winter (JJA) during 1948-1975. Significant correlations at 95\% level are shaded
The correlations change significantly when we consider Period II (Fig. 6). The connection with the tropical Pacific weakens, remaining only a small region of positive correlation in the central equatorial Pacific. These changes in correlation between the different periods was reported also in Barreiro (2009), who found a decrease in the predictability of the mean surface air temperature after mid-1970s mainly due to changes in the ENSO signal over SESA for late fall and winter. On the other hand, the South Atlantic Ocean becomes highly correlated with the ocurrence of warm nights in this period. This ocean shows alternate centres of significant negative (Tropical Atlantic), positive (southwestern Atlantic) and negative (Drake Passage) correlation. The SLPa regression map for this period shows that the Southern Oscillation Index (SOI) structure weakens substantially and a new seesaw pattern appears between the tropical Pacific and tropical Atlantic Oceans (Fig. 6b). At upper levels the anomalies are largest over tropical South America and a strong vortex centered at about $40^{\circ} \mathrm{S}, 30^{\circ} \mathrm{W}$ is clearly seen. This structure is also present during Period I, but is much weaker.

There are some studies suggesting a change in ENSO evolution after the "76 climate shift (Rasmusson and Carpenter 1982; Wang 1995; Trenberth and Stepaniak 2001; e.g.). These studies show that before 1976 the ENSO events started along the Peruvian coast in the eastern side of the tropical Pacific and developed westward toward the
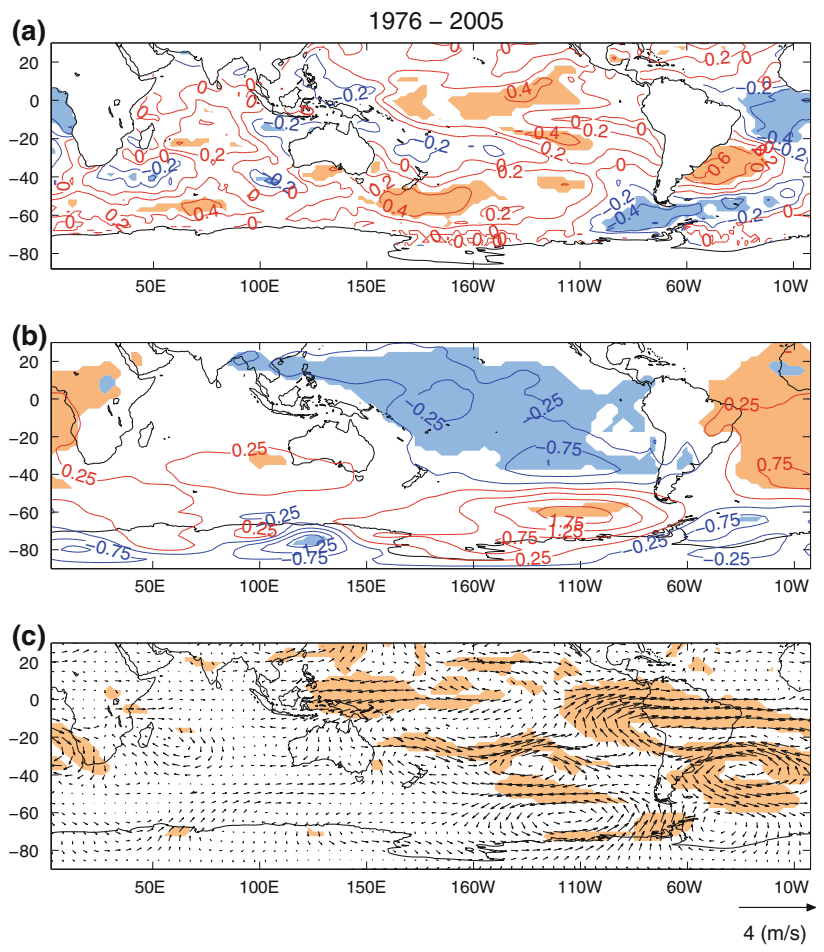

Fig. 6 Same as Fig. 5, but for the period 1976-2005 
central region, while ENSO events after 1976 tend to start in the central Pacific Ocean and develop to the east.

To address if these change in ENSO evolution after 1976 altered the teleconnection to Uruguay and its influence on the occurrence of warm nights (TN90) we constructed composites of El Niño minus La Niña for JJA(0) events before and after the 1976 climate shift (the " 0 " indicates that we consider the season previous to the peak of ENSO). El Niño and La Niña events were defined using the Oceanic Niño Index (ONI) (http://www.cgd.ucar.edu/ cas/ENSO/enso.html). The ONI considers the moving average of SST anomalies during 3 months in the region Niño $3.4\left(5^{\circ} \mathrm{N}-5^{\circ} \mathrm{S}, 120-170^{\circ} \mathrm{W}\right)$. The base period is the 1971-2000 and the ONI started in 1950. Table 1 presents the El Niño and La Niña years for JJA in the two periods considered. According to the ONI there are seven warm events and 11 cold events during Period I, and 10 warm events and six cold events during Period II. We also constructed the composites during non-ENSO years as follows: we consider 3 years which are above (below) one standard deviation of the TN90 index for each period, that are nonENSO years according to the ONI index. The years that satisfy these requirements are, for Period I: 1958-19591961 (>1 std) and 1952-1962-1966 (<-1std); for Period II: 1978-2001-2005 (>1 std) and 1993-1996-2003 (<-1 std). It is worth mentioning that years 2001 and 2005 are the largest values of the complete time series of TN90. Figure 7 shows the composites of SSTa, SLPa and wind anomalies at $200 \mathrm{hPa}$ level during the ENSO events of Period I. As expected, the positive SSTa in the Tropical Pacific Ocean has the maximum next to the coast of South America and extends meridionally between $30^{\circ} \mathrm{N}$ and $25^{\circ} \mathrm{S}$. At the same time there are negative SSTa in the SPCZ region and in the Central South Pacific. The high similarity between the regression maps for TN90 and the composite of ENSO events for JJA(0) for SST, SLP and $200 \mathrm{hPa}$ winds during the first period (compare Figs. 5, 7) strongly suggests that the interannual variability of warm nights in Uruguay during the winter season were highly associated

Table 1 Set of El Niño and La Niña events for JJA(0), based on ONI index for the periods: 1950-1975 and 1976-2005

\begin{tabular}{lll}
\hline Periods & El Niño & La Niña \\
\hline 1950-1975 & $1951-1957-1963$ & $1950-1954-1955$ \\
& $1965-1968-1969$ & $1956-1964-1967$ \\
& 1972 & $1970-1971-1973$ \\
& & $1974-1975$ \\
$1976-2005$ & $1976-1977-1983$ & $1984-1988-1995$ \\
& $1986-1987-1991$ & $1998-1999-2000$ \\
& $1994-1997-2002$ & \\
& 2004 & \\
\hline
\end{tabular}

with ENSO events. Moreover the structures of the atmospheric anomalies associated with warm nights during nonENSO years are different from those of the regression maps shown in Fig. 5, particularly at upper levels (Fig. 8). As during ENSO events, during non-ENSO years warm nights are related with an increase in the northerly flow consequence of a weakened south Pacific anticyclone. However, the main center of negative SLPa in the Pacific is located further southeast compared to that during ENSO years.

Figure 9, shows the composites for ENSO years during Period II. It shows that the SST anomalies in the tropical Pacific were highly confined to the equatorial region with small amplitude next to the coast of South America. Moreover, there is a significant negative SST anomaly in the cold tongue region of the Atlantic Ocean (Fig. 9a). Comparison with Fig. 6 shows that interannual variability of warm nights over Uruguay was not dominated by ENSO, but by other atmospheric processes.

The composites for non-ENSO years provide further insights (Fig. 10). During non-ENSO years the ocurrence of warm nights is associated with an intensification of the South Atlantic Subtropical high and the development of a continental low in subtropics, a configuration that leads to stronger (warm) northerly flow. Moreover, for the $200 \mathrm{hPa}$ wind the most relevant feature is the large anticyclonic anomaly centered at about $40^{\circ} \mathrm{S}-30^{\circ} \mathrm{W}$.
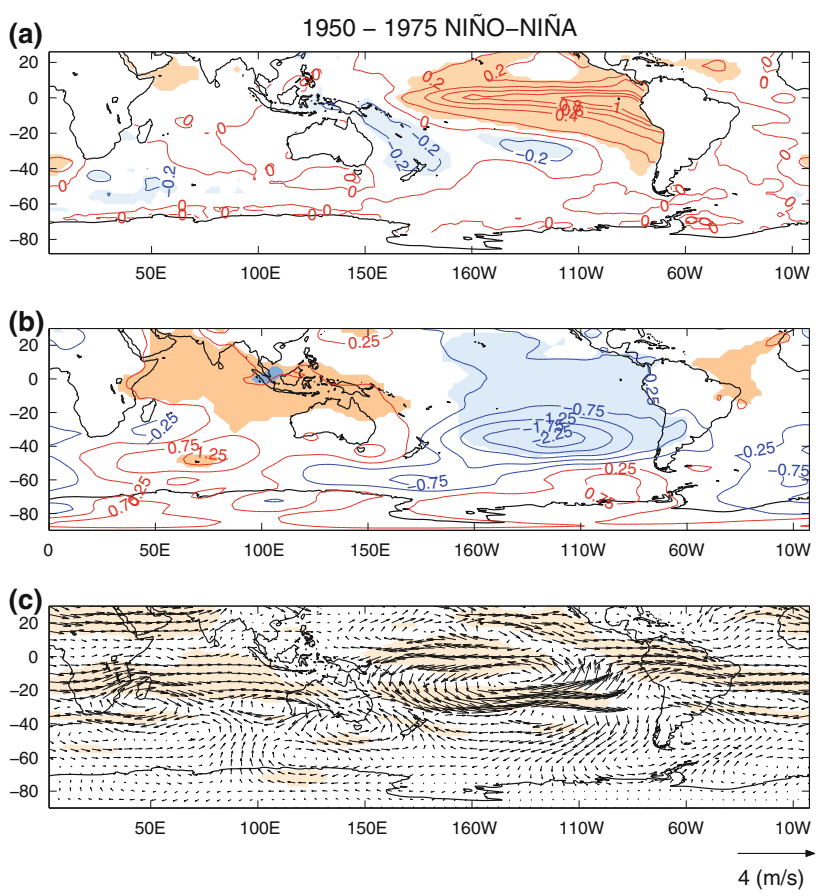

Fig. 7 Composites El Niño-La Niña of SSTa (a), SLPa (b) and vector wind at $200 \mathrm{hPa}(\mathbf{c})$ for JJA (0) during the period 1950-1975. Significant correlations at $95 \%$ level are shaded 

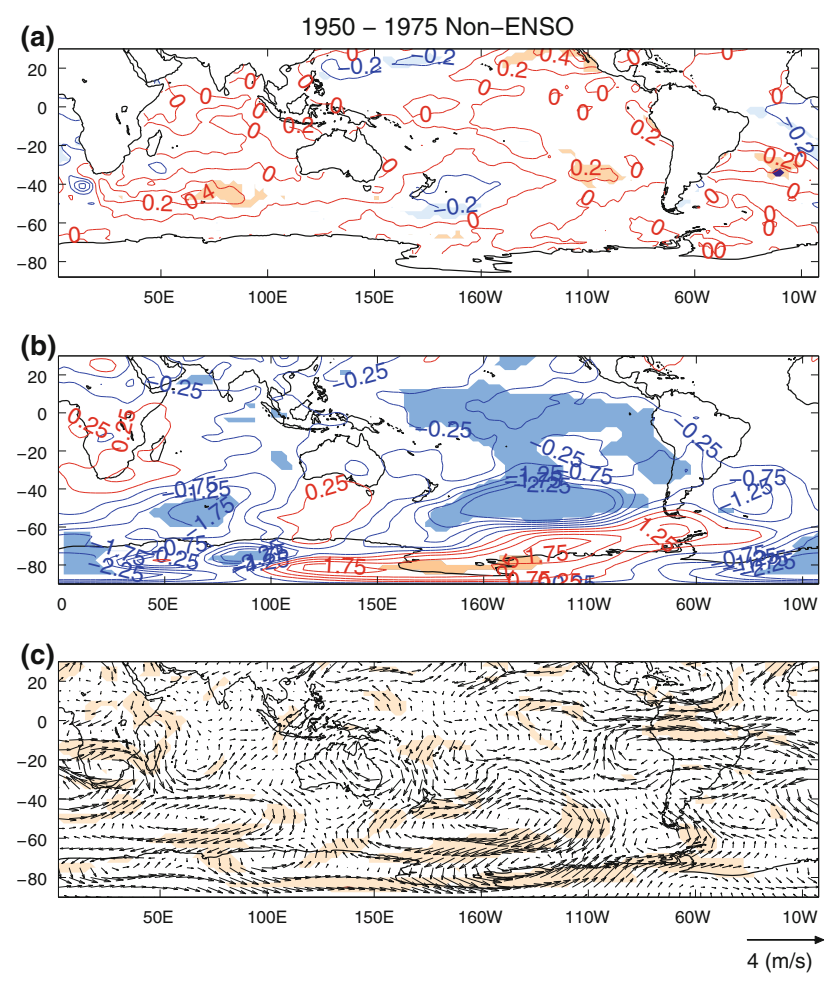

Fig. 8 Composites of Non-ENSO events of SSTa (a), SLPa (b) and vector wind at $200 \mathrm{hPa}$ (c) for JJA for the period 1950-1975. Significant correlations at $95 \%$ level are shaded
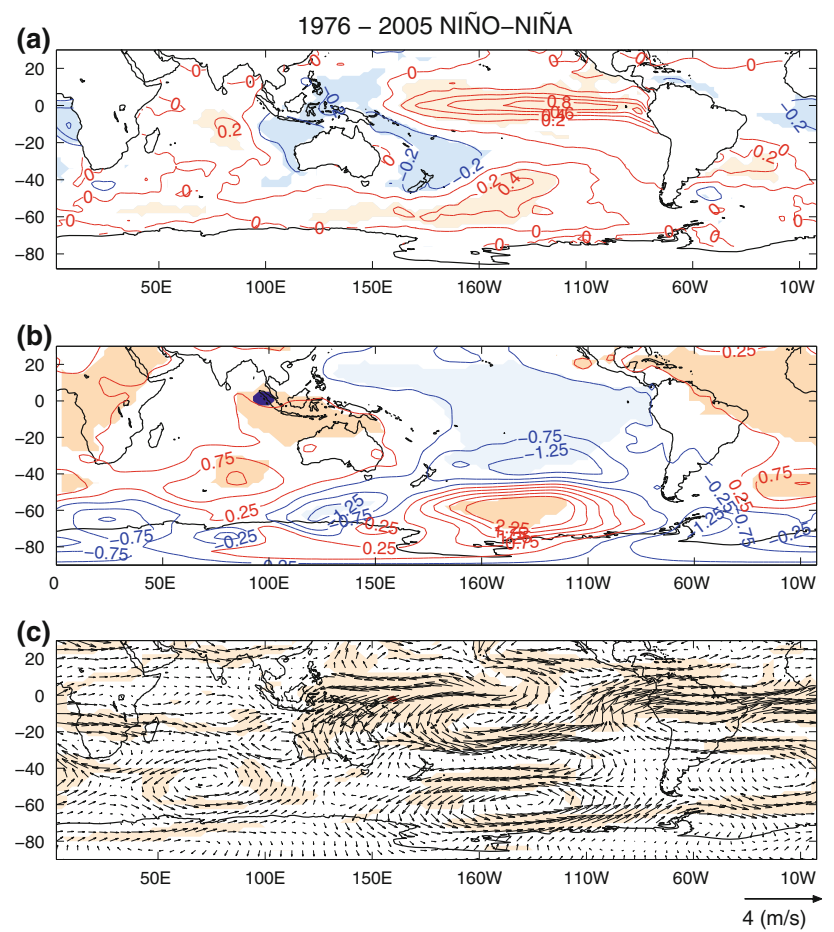

Fig. 9 Same as Fig. 7, but for the period 1976-2005

The composite of SSTa shows an alternate pattern of negative and positive anomalies in the Atlantic Ocean, with a similar structure as found in the correlation map with
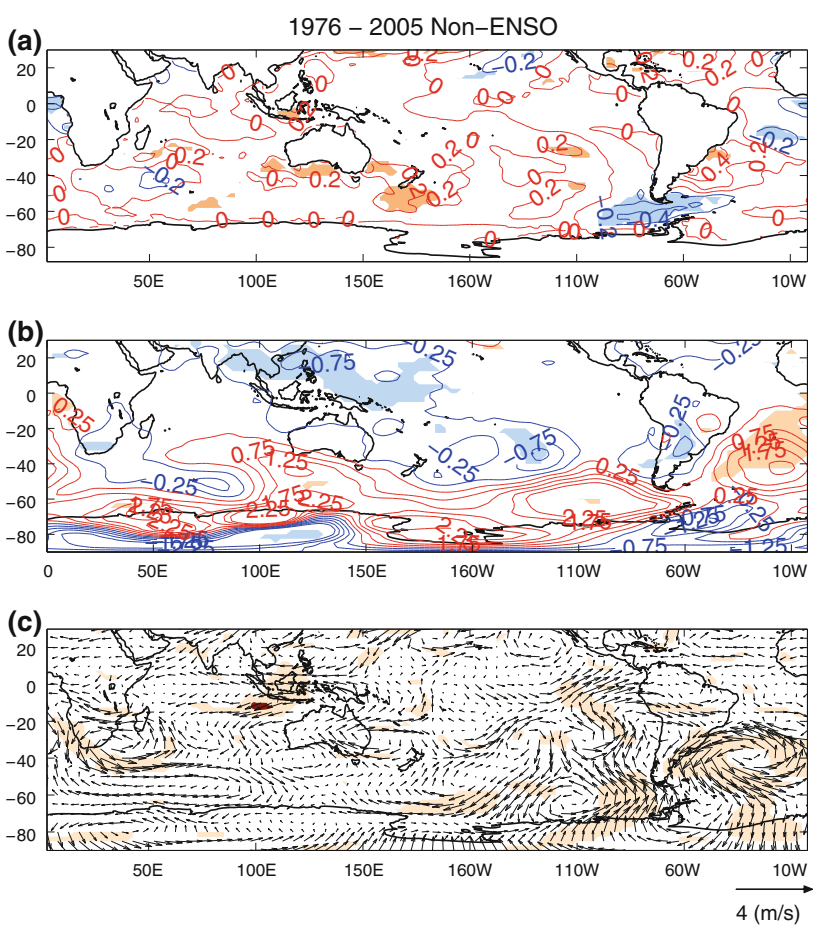

Fig. 10 Same as Fig. 8, but for the period 1976-2005

TN90 for Period II (see Fig. 6). Overall, the patterns of the composite for non-ENSO years in Period II are similar as the ones obtained in the regression maps with the warm nights in Period II. This is particularly true in the South Atlantic region, and suggests that since 1976 atmospheric variability not related to ENSO has dominated the interannual variance of the occurrence of warm nights over Uruguay.

A comparison of the results for the two periods hints that the change in the evolution of ENSO had a major impact on the variability of winter warm nights over Uruguay. Since the largest differences between the SSTa patterns in JJA(0) of ENSO events are close to the western coast of South America, this study suggests that the SSTa in this region are instrumental in inducing the teleconnections that will affect the climate over SESA. In the absence of these teleconnections the internal atmospheric variability dominates the behaviour of warm nights over Uruguay during winter (as in Period II). Interestingly, the structure of the atmospheric variability during non-ENSO years that is related to warm nights is different in the two periods, but both patterns favour the entrance of warm northern flow to the region under study (compare Figs. 8, 10).

\section{Summary and discussion}

The relationship between the interannual variability of indices of extreme minimum temperature from a dense 
network over Uruguay and the large scale atmospheric circulation was analyzed before and after the climate shift of 1976/1977. We considered detrended percentile-based indices TN90 and TN10 that represent unusually warm or cold nights; respectively. Since they are referred to the local climate our results are comparable at the global or regional scales. Two periods of 30 years each: 1946-1975(Period I) and 1976-2005 (Period II) at the seasonal scale were compared as an indicator of multidecadal variability.

The analysis of the linear correlation between the global SST anomalies and the extreme indices suggests overall robust changes in this relationship for the equatorial Pacific and the Indian Oceans.

During the austral summer of Period I negative anomalies in the tropical Indian Ocean and in small regions close to the coast of South America at about $40^{\circ} \mathrm{S}$ are associated with a higher occurrence of cold nights in Uruguay. At the same time, the atmospheric configuration shows a SAM in its negative phase with a low pressure anomaly centered off Uruguay that favours the entrance of cold air from the south. Interestingly, during this period the SAM index was predominantly in its negative phase (Marshall 2003). On the other hand, the analysis in the present climate (1976-2005) shows no relationship at all with the SAM. Instead, cold nights are associated with a cyclonic anomaly over SESA at upper levels. Moreover, there are significant positive correlations with the SSTa in the SPCZ region and negative correlations over the western South Atlantic and eastern South Pacific. Using an AGCM coupled to a slab ocean we showed that the cyclonic circulation that is related to TN10 is independent of ENSO and forces the SSTa off Uruguay and in the southeastern Pacific.

During the winter season the large scale pattern associated with the occurrence of warm nights (TN90) shows significant interdecadal variability. While in 1948-1975 the El Niño phenomenon clearly is the dominant structure in all regression maps of TN90, internal atmospheric variability plays an important role after 1976 . The composites of El Niño minus La Niña events for JJA(0) show changes in the spatial structure of El Niño events after the 1976 climate shift, so that in the present climate the SSTa are confined to the equatorial zone (see also Trenberth and Hurrel 1994; Wang 1995, etc.). Comparing the composites of El Niño-La Niña and the regression maps of TN90 for the period 1976-2005 (Figs. 6, 9), it is clear that ENSOinduced anomalies are mainly confined to the tropical band. During this period the variability of TN90 over Uruguay is highly associated with a barotropic anticyclonic anomaly situated in the south Atlantic that is independent of ENSO. This circulation anomaly strengthens the northerly flow into Uruguay thus favouring the ocurrence of warm nights.
The current analysis shows evidence of changes in the relationship of extreme temperature events with large scale patterns after the 1976 climate shift. In the present climate, in both seasons analyzed, extreme events are associated with a vortex circulation anomaly at upper levels that needs to be further studied. Our results also suggest that the occurrence of extreme temperature events are strongly correlated with changes in the ENSO evolution occurred around 1976. Since then the ENSO signal in extratropical South America seems to be weaker, with an increase of the influence of atmospheric internal variability, particularly during the winter season. Evidence of the influence of one of the principal modes of variability of the Southern Hemisphere, the Southern Annular Mode, was also shown, particularly for the summer season before 1976 .

Acknowledgments The authors want to thanks to the comments of the anonymous reviewers which contributed in improving this work. The research leading to these results has received funding from the European Community's Seventh Framework Programme (FP7/20072013)under Grant Agreement $N^{\circ} 212492$ (CLARIS LPB. A EuropeSouth America Network for Climate Change Assessment and Impact Studies in La Plata Basin).

\section{References}

Agosta E, Compagnucci R (2008) The 1976/77 Austral summer climate transition effects on the atmospheric circulation and climate in southern South America. J Clim 21:4365-4383. doi: 10.1175/2008JCLI2137.1

Alexander LV, Zhang X, Peterson TC, Caesar J, Gleason B, Klein Tank AMG, Haylock M, Collins D, Trewin B, Rahimzadeh F, Tagipour A, Rupa Kumar A, Revadekar J, Griffiths G, Vincent L, Stephenson DB, Burn J, Aguilar E, Brunet M, Taylor M, New M, Zhai P, Rusticucci M, Vazquez-Aguirre JL (2006) Global observed changes in daily climate extremes of temperature and precipitation. J Geophys Res 111:D05109. doi:10.1029/2005 JD006290

Antico PL (2008) Relationships between autumn precipitation anomalies in southeastern South America and El Niño events classification. Int J Climatol 29:719-727. doi:10.1002/joc.1734

Arblaster JM, Meehl GA (2006) Contributions of external forcings to southern annular mode trends. J Clim 19:2896-2905. doi: 10.1175/JCLI3774.1

Barreiro M (2009) Influence of ENSO and the South Atlantic Ocean on climate predictability over Southeastern South America. Clim Dyn. doi:10.1007/s00382-009-0666-9

Barros VR, Grimm AM, Doyle ME (2002) Relationship between temperature and circulation in southeastern South America and its influence from El Niño and La Niña events. J Meteorol Soc Jpn 80:21-32

Barrucand M, Rusticucci M, Vargas W (2008) Temperature extremes in the south of Sotuh America in relation to Atlantic Ocean surface temperature and Southern Hemisphere circulation. J Geophys Res 113:D20111. doi:10.1029/2007JD009026

Boulanger J-P, Leloup J, Penalba O, Rusticucci M, Lafon F, Vargas W (2005) Observed precipitation in the Paraná-Plata hydrological basin: long-term trends, extreme conditions and ENSO teleconnections. Clim Dyn 24:393-413. doi:10.1007/s00382004-0514-x 
Frich P, Alexander LV, Della-Marta P, Gleason B, Haylock M, Klein Tank AMG, Peterson T (2002) Observed coherent changes in climatic extremes during the second half of the twentieth century. Clim Res 19:193-212

Gillett NP, Thompson DWJ (2003) Simulation of recent Southern Hemisphere climate change. Science 302:273-275

Haylock MR, Peterson TC, Alves LM, Ambrizzi T, Anunciacao YMT, Baez J, Barros V, Berlato MA, Bidegain M, Coronel G, Corradi V, Garcia VJ, Grimm AM, Karoly D, Marengo JA, Marino MB, Moncunill DF, Nechet D, Quintana J, Rebello E, Rusticucci M, Santos JL, Trebejo I, Vincent LA (2006) Trends in total extreme South American rainfall in 1960-2000 and links with sea surface temperature. J Clim 19:1490-1512

Kalnay E, Kanamitsu M, Kistler R, Collins W, Deaven D, Gandin L, Iredell M, Saha S, White G, Woollen J, Zhu Y, Leetmaa A, Reynolds B, Chelliah M, Ebisuzaki W, Higgins W, Janowiak J, Mo KC, Ropelewski C, Wang J, Jenne R, Joseph D (1996) The NCEP/NCAR 40-year reanalysis project. Bull Am Meteorol Soc 77:437-471

Kayano MT, Andreoli R (2007) Relations of South American summer rainfall interannual variations with the Pacific decadal oscillation. Int J Climatol 27:531-540. doi:10.1002/joc.1417

Kenyon J, Hegerl G (2008) Influence of modes of climate variability on global temperature extremes. J Clim 21:3872-3889

Kidson J (1999) Principal modes of Southern Hemisphere lowfrequency variability obtained from NCEP-NCAR reanalyses. J Clim 12:2808-2830

Mantua N, Hare S (2002) The Pacific decadal oscillation. J Oceanogr $58: 35-44$

Marengo J, Camargo C (2008) Surface air temperature trends in Southern Brasil for 1960-2002. Int J Climatol 28:893-904. doi: $10.1002 /$ joc. 1584

Marengo J, Rusticucci M, Penalba O, Renom M (2010) An intercomparison of model-simulated in extreme rainfall and temperature events during the last half of XX century. Part 2: historical trends. Clim Change 98(3):509-529. doi:10.1007/ s10584-009-9743-7

Marshall G (2003) Trends in the southern annular mode from observations and reanlysis. J Clim 16:4134-4143

Marshall GJ, Stott PA, Turner J, Connolley WM, King JC, LachlanCope TA (2004) Causes of exceptional atmospheric circulation changes in the Southern Hemisphere. Geophys Res Lett 31:L14205. doi:10.1029/2004GL019952

Mo KC (2000) Relationships between low-frequency variability in the Southern Hemisphere and sea surface temperature anomalies. J Clim 13:3599-3610

Molteni F (2003) Atmospheric simulations using a GCM with simplified physical parametrizations. I: Model climatology and variability in multi-decadal experiments. Clim Dyn 20:175191
Muller GV, Ambrizzi T (2007) Teleconnection patterns and Rossby wave propagation associated to generalizad frosts over southern South America. Clim Dyn. doi: 10.1007/s00382-007-0253-x

Overland J, Adams J, Bond N (1999) Decadal variability of the Aleutian low and its relation to high-latitude circulation. J Clim 12:1542-1548

Rasmusson E, Carpenter T (1982) Variations in tropical sea surface temperature and surface wind fields associated with the Southern oscillation/El Niño. Mon Weather Rev 110:354-384

Rusticucci M, Barrucand M (2004) Observed trends and changes in temperature extremes over Argentina. J Clim 17:4099-4107

Rusticucci M, Renom M (2008) Variability and trends in indices of quality-controlled daily temperature extremes in Uruguay. Int $\mathbf{J}$ Climatol 28:1083-1095. doi:10.1002/joc.1607

Rusticucci M, Marengo J, Penalba O, Renom M (2010) An intercomparison of model-simulated in extreme rainfall and temperature events during the last half of the twentieth century. Part 1: mean values and variability. Clim Change 98(3):493508. doi:10.1007/s10584-009-9742-8

Silvestri G, Vera C (2009) Nonstationary impacts of the Southern annular mode on Southern Hemisphere climate. J Clim 22:6142-6148. doi:10.1175/2009JCLI3036.1

Smith TM, Reynolds RW, Peterson TC, Lawrimore J (2008) Improvements to NOAA's historical merged land-ocean surface temperature analysis (1880-2006). J Clim 21:2283-2296

Thompson DWJ, Solomon S (2002) Interpretation of recent Southern Hemisphere climate change. Science 296:895-899

Thompson DWJ, Wallace JM (2000) Annular modes in the extratropical circulation. Part I: Month-to-month variability. J Clim 13:1000-1016

Trenberth K (1990) Recent observed interdecadal climate change in the Nothern Hemisphere. Bull Am Meteorol Soc 71:988-993

Trenberth K, Hurrel J (1994) Decadal atmosphere-ocean variation in the Pacific. Clim Dyn 9:303-319

Trenberth K, Stepaniak P (2001) Indices of El Niño evolution. J Clim 14:1697-1701

Vincent L, Peterson T, Barros V, Marino M, Rusticucci M, Carrasco G, Ramirez E, Alves L, Ambrizzi T, Berlato M, Grimm A, Marengo M, Molion L, Moncunill D, Rebello E, Anunciacao Y, Quintana J, Santos J, Baez J, Coronel G, Garcia J, Trbejo I, Bidegain M, Haylock M, Karoly D (2005) Observed trends in indices of daily temperature extremes in South America 1960-2000. J Clim 18:5011-5023

Wang B (1995) Interdecadal changes in El Niño onset in the last four decades. J Clim 8:267-285

Zhang Y, Wallace J, Battisti D (1997) ENSO-like interdecadal variability: 1900-93. J Clim 10:1004-1020

Zhang X, Hegerl G, Zwiers FW, Kenyon J (2004) Avoiding inhomogeneities in percentile-based indices of temperature extremes. J Clim 18:1641-1651 